\title{
Do Adolescents' Evaluations of Exclusion Differ Based on Gender Expression and Sexual Orientation?
}

\author{
Justin E. Heinze* \\ University of Michigan
}

\author{
Stacey S. Horn \\ University of Illinois-Chicago
}

Previous research focused on sexual prejudice has shown that lesbian and gay adolescents are at greater risk of peer harassment and victimization than their straight counterparts. Peer victimization such as exclusion, however, may also be related to conventional expectations adolescents hold about their social environment. This study examined adolescents' $(N=1069)$ attitudes and reasoning about the exclusion of peers based on sexual orientation and gender nonconformity. Results indicate that although participants reported it was more acceptable to exclude their gay or lesbian, as opposed to straight, peers, gender nonconformity was also a distinguishing factor. Whereas mannerism and activity nonconforming gay targets were rated less positively than similarly nonconforming straight targets, straight appearance nonconforming targets were not evaluated differently than gay appearance nonconforming targets. Further, the types of reasoning adolescents used to justify their exclusion judgments varied by sexual orientation and gender nonconformity of the target.

With the onset of puberty, harassment related to sexuality and gender expression becomes more prevalent and is often directed at same-sex peers (Craig, Peplar, Connolly, \& Henderson, 2001; Horn, 2006a, 2007; Pascoe, 2011; Poteat, Kimmel, \& Wilchins, 2011). As children move into adolescence, gender roles become more salient and limiting, while adherence to these norms becomes much more important (Pascoe, 2011). Even as individuals are trying to figure

\footnotetext{
${ }^{*}$ Correspondence concerning this article should be addressed to Justin Heinze, Department of Health Behavior and Health Education, 1415 Washington Heights, SPH I, Rm 3703, University of Michigan, Ann Arbor, MI 48109 [e-mail: jheinze@umich.edu].

This research was supported in part by a research grant to the first author from the Wayne F. Placek fund of the American Psychological Foundation.
} 
out their own sexual and gender identity in adolescence, they are also policing their peers regarding this process. Adolescents may perceive exclusion as a legitimate way to socially sanction individuals whose personal attributes or identity expressions fall outside of what is considered acceptable according to social norms regarding gender and sexuality. Further, recent research on harassment and victimization related to sexual orientation suggests that adolescents' perception of appropriate gender norms regarding dress, physical appearance, and mannerisms influence their judgments about how to treat their peers as much as, or perhaps even more than, their attitudes about sexual orientation (Blashill \& Powlishta, 2009; Horn, 2007; Pascoe, 2011). Building upon this previous research, the purpose of this study was to investigate the ways in which gender nonconformity and sexual orientation relate to adolescents' social reasoning about peer group exclusion. To frame our research questions and investigate these issues, we utilize two related theories of social cognitive development: social cognitive domain theory, as well as social reasoning development theory recently proposed by Killen and colleagues (Rutland, Killen, \& Abrams, 2010; Killen \& Rutland, 2011).

\section{Social Cognitive Domain Theory}

A growing body of research on children and adolescents' reasoning about peer group exclusion suggests that in evaluating issues of exclusion, individuals draw upon their knowledge of fairness and individual rights, their understanding of groups as social systems based on consensually agreed upon norms, conventions, and identities, as well as their sense of autonomy and personal choice (Horn, 2003; Killen, 2007; Killen, Lee-Kim, McGlothlin, \& Stangor, 2002; Mulvey, Hitti, Rutland, Abrams, \& Killen, 2014). The central premise of social cognitive domain theory (Turiel, 1983) is that evaluative social judgments are multifaceted and draw from a number of conceptual frameworks or domains rather than a single structure of sociomoral reasoning. Three basic conceptual frameworks or domains are posited by domain theory: morality, societal convention, and the personal. Concepts of morality address issues of human welfare, rights, and fairness and are constructed out of the child's early social interactions around events, such as unprovoked hitting and hurting, that have intrinsic effects upon another person (Turiel, 1983). Morality (defined in terms of justice, welfare, rights) can be distinguished from concepts of social conventions, which are the consensually determined standards of conduct particular to a given social group. Whereas morality and convention deal with aspects of interpersonal regulation, concepts of personal issues refer to actions that comprise the private aspects of one's life, such as the contents of a diary, and issues of preference and choice (e.g., friends, music, hairstyle) rather than right or wrong. Nucci (1996) proposed that desire for control over the personal domain emerges from the need to establish boundaries between 
the self and others, and is critical to the establishment of individual autonomy and identity.

In extending social cognitive domain theory to intergroup contexts, Killen and colleagues suggest that domain reasoning is influenced by individuals' group membership and identification (Killen, 2007; Rutland et al., 2010). The interplay between the self and the group is argued to influence exclusionary attitudes and behavior in that the demands of group cohesion and promotion can legitimate social conventions as a justification for exclusion, especially if the situation is ambiguous or complex.

Research utilizing these approaches provides evidence that individuals of all ages draw upon these domains of social knowledge in reasoning about exclusion. How these domains of knowledge get coordinated and applied to issues of peer group inclusion/exclusion changes, however, as children move into adolescence (Horn, 2003, 2006b; Killen et al., 2002). Many adolescents view exclusion that is based solely on one's social group membership in a particular race, gender or peer group as wrong from a moral viewpoint (it is unfair or hurtful; Horn, 2003). Adolescents, however, are more likely than children to evaluate excluding someone from a peer group or friendship group as all right (Killen, 2007) and more frequently justify these judgments by making appeals to group functioning, group norms, or personal choice (Horn, 2003; Rutland et al., 2010). These results suggest that as children get older they have an increased knowledge of the conventional features of groups (group identity, group functioning) that are legitimately necessary to the organization and maintenance of groups, as well as an expanded understanding of issues that are up to the individual to decide (Nucci, 1996).

There is some preliminary evidence that social norms regarding gender and gender roles are related to children and adolescents' evaluations of exclusion based on gender. Killen and her colleagues found that gender exclusion is less often evaluated as wrong than exclusion based on race (Killen et al., 2002). Children and adolescents were also more likely to rely on conventions regarding gender in justifying exclusion. Applying a similar framework to exclusion based on sexual orientation, Horn (2006a) found that ninth-graders were less likely than older adolescents to evaluate exclusion of lesbian or gay peers as wrong and used more conventional and personal reasoning in justifying their decisions. Less understood are the ways in which social norms regarding gender expression in terms of appearance and mannerisms influence adolescents' evaluations of exclusion, and whether those evaluations are related to sexual orientation.

\section{Social Norms, Gender, Sexual Orientation, and Peer Harassment}

Social norms regarding gender and sexuality are particularly salient in adolescence (Craig et al., 2001; Pascoe, 2011). Heterosexuality is the prevailing norm in the majority of middle and high schools in the United States and 
adolescents are socialized, both informally and formally, toward heterosexual behaviors and relationships (Mandel \& Shakeshaft, 2000). Harassment based on sexuality becomes much more salient in adolescence due to normative biological development (puberty), as well as developmental changes within the peer group structure (Craig et al., 2001). Moreover, research with adolescents on homophobia and anti-gay prejudice suggests that anti-gay attitudes are in place by early adolescence (Baker \& Fishbein, 1998; Mandel \& Shakeshaft, 2000; Poteat, Espelage, $\&$ Koenig, 2009) and that individuals who hold conventional beliefs about gender roles are more likely to be prejudiced and less likely to befriend a gay or lesbian person (Poteat et al., 2009). Interestingly, anti-gay language and harassment, while in part related to regulating peers' sexual orientation, is in large part used by adolescents to regulate each other's gender and gender expression (Horn, 2006b; Pascoe, 2011; Poteat et al., 2011). Individuals who fall outside the range of what is considered acceptable for their gender in terms of mannerisms, appearance, or activities can be targets of ridicule, teasing, and harassment from their peers (Horn, 2006b; Pascoe, 2011).

Despite the greater risk of victimization faced by adolescents who deviate from either gender or sexuality norms, relatively little work has focused on the interaction between sexual orientation and gender nonconformity, particularly as it relates to social exclusion. Previous work is mixed as to which individual characteristic (sexual orientation versus gender nonconformity) increase adolescents' vulnerability to negative evaluations, social exclusion and peer harassment. In adult samples, Schope and Eliason (2004), for example, found few differences in negative evaluations of gay and lesbian targets that were related to the targets' femininity or masculinity, and instead suggested that the targets' sexual orientation was the basis for negative reaction. In contrast, Blashill and Powlishta (2009) found that negative evaluations of gay males were related to both sexual orientation and gender role adherence, with gender roles having a more consistent effect. Whether there is additional risk associated with being both homosexual and gender nonconforming remains unclear. A young gay male who participates in stereotypically feminine activities, for example, may be at greater risk for harassment or exclusion than a gay male who adheres to masculine norms. Similarly, a heterosexual male who exhibits a gender nonconforming appearance may be at as much risk for peer sanction and harassment as a similar student who identifies as gay.

Even less research has examined what forms of gender nonconformity are related to greater rebuke from peers. Studies have shown that gay men are perceived to be more feminine and lesbian women more masculine than straight men and women, respectively (Fingerhut \& Peplau, 2006; Lehavot \& Lambert, 2007). Consequently, adolescents may hold stereotypic expectations about their lesbian or gay peers ("He's gay, so he doesn't like sports"). Such beliefs may mean adolescents are more tolerant of certain forms on nonconformity 
(e.g., cross-gender activities), but not others (e.g., acting or dressing like the opposite sex). One reason this may be the case, is that adolescents perceive certain types of gender transgressions as more deviant, and therefore as more of a risk to the "in-group" than others.

Recent research on intergroup dynamics and deviance evidences that individuals who deviate from the implicitly agreed upon norms of their in-group are viewed more negatively by their peers than out-group members who adhere to the in-group norms (Abrams, Rutland, \& Cameron, 2003; Killen, Rutland, Abrams, Mulvey, \& Hitti, 2012). Further, including the deviant in-group member is less favorable than excluding an out-group member who adheres to the groups norms, in part because the deviant in-group member is viewed as more of a risk to the coherence and maintenance of the group than the deviant out-group member (Killen et al., 2012). Thus, adolescents may view certain types of gender deviance (e.g., appearance, mannerisms) as more threatening to the construction and maintenance of gender roles and norms during this developmental period than other types of gender deviance (e.g., choice of activities).

Investigating these issues can further our understanding of how social norms about specific personal characteristics or identity expression influence reasoning about social exclusion. In addition, schools can be unsafe and inhospitable places for lesbian, gay, bisexual, transgender, and gender nonconforming young people due to social exclusion, ostracism, and harassment. Increasing our understanding of these issues can inform efforts to create safer schools for all young people.

\section{Overview of the Study and Hypotheses}

In this study, we investigated whether and how sexual orientation and different types of gender nonconformity were related to adolescents' judgments and reasoning about social exclusion of their peers. To investigate these questions we asked adolescents to respond to a series of scenarios about excluding individuals who varied in terms of their sexual orientation (heterosexual, gay, or lesbian) and nonconformity in gender expression (gender nonconforming in forms of appearance, mannerisms or activity). Adolescents were asked to evaluate whether they thought excluding someone from a peer group based on his/her sexual orientation and gender expression was wrong and to provide a reason for their evaluation. Consistent with previous research (Schope \& Eliason, 2004), we expected that adolescents would evaluate social exclusion of gay or lesbian peers as less wrong than straight peers. Further, we expected that type of gender nonconformity would be related to adolescents' judgments with exclusion of appearance nonconforming targets viewed as least wrong.

We also expected that an individual's sexual orientation and gender expression would be related to differences in reasoning about why excluding a target would be wrong or all right. Based on previous work suggesting early adolescents view 
decisions about friendships and peer groups in personal and conventional terms (Killen et al., 2002), we expected that adolescents would use more conventional and personal reasons in justifying their evaluations about excluding peers who were gay, lesbian, and gender nonconforming. In contrast, we anticipated greater use of moral and personal reasons for judgments about straight peers.

\section{Method}

\section{Participants and Procedures}

One thousand sixty-nine adolescents (female, $n=639$; male, $n=430$ ) attending two different schools participated in the study. The sample consisted of 9th-grade $(194$ male, 288 female, mean age $=15.0)$ 10th-grade (111 male, 166 female, mean age $=15.8)$ 11th-grade $(72$ male, 122 female, mean age $=16.8)$, and 12 th-grade $(53$ male, 61 female, mean age $=17.8$ ) students. The largest proportion of students was European American (29.7\%), followed by Asian American (27.4\%), Latino (19.4\%), and African American (14.5\%). Relatively few students identified as bicultural, Middle-Eastern or Native American (5.9\%, 2.9\%, and $0.3 \%$, respectively). Students attended either an urban college preparatory high school (School A) located within a large Midwestern city $(n=575)$, or a larger suburban high school (School B) located just outside of the same city $(n=494)$. Further, we excluded 17 participants because they identified as other than heterosexual.

Participants completed the questionnaire in their required advisory period, English, health, or social studies class. Participants were presented a $2 \times 3$ series of scenarios depicting individuals who were gay or straight, and gender nonconforming in appearance, mannerisms, or choice of extracurricular activity (Horn, 2007). For example, "Ashley is a straight female high school student. She plays on the school volleyball team. She is a 'B' student. She dresses differently from most of the other girls at school. For example she has a crew cut, and never wears make-up or dresses." Participants were asked to evaluate whether or not they thought it was wrong (judgment) for the students to exclude the target individual and to provide a reason for why (justifications). Participants were randomly assigned to read stories about either male or female targets. The six scenarios were counterbalanced to account for order of presentation.

\section{Measures}

Exclusion treatment judgments. Participants evaluated whether they thought it was right or wrong for individuals to exclude the target. Judgments were assessed on a five-point Likert scale $(1=$ completely wrong; $3=$ neither right nor wrong; $5=$ completely all right). 
Exclusion treatment justifications. In addition to an evaluation judgment, for each story we asked participants to choose, from a set of eleven responses, the reasons that best reflected their opinion for why they thought the action (exclusion) was right or wrong. The responses used were developed from pilot interviews and informed by social cognitive domain theory (Turiel, 1983), and prior work on sexual prejudice (Herek, 1994). In addition to moral ("It is unfair/hurtful to him"), conventional ("He dresses or acts the way a [guy] in our society should") and personal ("Who you hand out with is a matter of personal choice) domain categories, we also included as response options types of reasoning that have been related to sexual prejudice in social psychological research (e.g., that the "gay" person might hit on them, that homosexuality is disgusting; see Heinze \& Horn, 2009, for a complete list). Participants could choose more than one response. Scores were calculated as the proportion of a participants' response that fell into each justification type. Log-linear transformations were conducted on the proportional scores to adjust for nonnormality (Winer, Brown, \& Michels, 1991).

\section{Results}

Given previous research reporting differences in individuals' gender role attitudes for females and males, as well as differences in prejudice toward lesbians versus gay men (Schope \& Eliason, 2004), we ran and report separate analyses based on the gender of the target. Because significant school differences related to adolescents sexual prejudice have been reported elsewhere (Horn \& Szalacha, 2009), we controlled for school in all analyses.

\section{Exclusion Judgments}

To investigate the relationship between exclusion judgments, sexual orientation and gender expression, we conducted two 2 (sexual orientation: gay/lesbian, straight) $\times 3$ (gender expression: appearance nonconforming, mannerisms nonconforming, activity nonconforming) $\times 4$ (grade: freshman, sophomore, junior, senior) $\times 2$ (participant gender: male, female) repeated measures ANCOVAs with sexual orientation and gender identity as repeated measures (one for male targets and one for female targets).

Male targets. Whereas main effects for sexual orientation and gender expression did not emerge, the hypothesized interaction between sexual orientation and gender expression did occur for male targets $F(2,1088)=3.61, p<.05$ $\eta^{2}=.01$. Follow-up tests of simple effects supported our hypotheses regarding type of gender nonconformity. Overall, for gay targets, participants were significantly more likely to say it would be OK to exclude their appearance $(M=2.48$, $S E=.05)$ and mannerism $(M=2.47, S E=.05)$ nonconforming peers, than their 
activity nonconforming peers $(M=2.37, S E=.05 ; t(570)=2.58, p<.01 ; t(567)$ $=2.07, p<.05$, respectively). A similar pattern emerged for straight targets, with adolescents indicating it was more acceptable to exclude appearance $(M=2.49$, $S E=.05)$ and mannerism $(M=2.38, S E=.05)$ nonconforming peers relative to activity nonconformers $(M=2.23, S E=.05 ; t(568)=4.38, p<.001 ; t(561)$ $=1.96, p=.05$, respectively). Notably, the difference between appearance and mannerism nonconforming straight targets was also significant $(t(559)=2.21$, $p<.05)$.

Further, participants evaluated excluding gay targets who were nonconforming in mannerisms or activities as less wrong than straight targets who were nonconforming in these same ways $(t(561)=2.75, p<.01 ; t(567)=2.52, p<$ .05 , respectively). Interestingly, there was no difference between gay and straight appearance nonconforming targets suggesting that this type of nonconformity is viewed as equally negative for both gay and straight males.

Although no overall grade differences were found in exclusions judgments, judgments did differ significantly by gender of the participant. Male adolescents in this sample were more likely to agree that it would be OK to exclude their peers, across all scenarios, $(M=2.65, S E=.07)$ than their female counterparts $(M=$ $2.16, S E=.06, p<.01)$.

Female targets. When the scenarios depicted females targets, a main effect emerged for sexual orientation $F(1,525)=13.78, p<.001 \eta^{2}=.03$. Overall, participants indicated that it would be more OK to exclude their lesbian peers $(M=2.38, S E=.04)$ compared to their straight counterparts $(M=2.26$, $S E=.04, p<.001)$. Gender nonconformity was not a significant predictor of exclusion for lesbian targets.

As with male targets, a significant between-subjects effect based on participant gender was obtained $\left(F(1,525)=17.53, p<.001 \eta^{2}=.03\right)$ with male adolescents $(M=2.52, S E=.09)$ saying it was more OK to exclude lesbian targets, in general, compared to females $(\mathrm{M}=2.13, S E=.09, p<.01)$. Grade differences also emerged with freshman $(M=2.44, S E=.06)$ saying, in general, it would be more OK to exclude their lesbian peers than sophomores $(M=2.13, S E=.09, p<.05)$. Differences between other grades were not significant.

\section{Exclusion Justifications}

To investigate the relationship between participants' justifications for why exclusion was right or wrong, we conducted a 2 (sexual orientation: gay/lesbian, straight) $\times 3$ (gender expression: appearance nonconforming, mannerisms nonconforming, activity nonconforming) $\times 11$ (justification: affirms norms, fairness, hit on me, human equality, negates norms, personal choice, God's law, it's unnatural/disgusting, people need to belong, religious human equality, might 
think they're gay) repeated measures ANCOVA with sexual orientation, gender expression and justification as repeated measures. To reduce the complexity of the analysis and because significant differences on judgments were obtained, we controlled for participant grade and participant gender by including them with school as covariates.

Male targets. $\quad$ A main effect for justification $(F(10,5,850)=2.70, p<$ $\left..01 \eta^{2}=.01\right)$ emerged. The main effect was qualified by two significant twoway interactions between justification type and gender expression $(F(20,11,700)$ $\left.=5.52, p<.001 \eta^{2}=.01\right)$, and between justification type and target sexual orientation $\left(F(10,5,850)=6.10, p<.001 \eta^{2}=.01\right)$. The hypothesized threeway interaction between justification type by gender expression and target sexual orientation $\left(F(20,11,700)=1.74, p<.05 \eta^{2}=.003\right)$ also emerged.

As seen in Table 1, participants tended to use justifications for straight nonconforming targets that appeal to the moral domain issues of fairness and not harming others (fairness, human equality, need to belong, religious human equality). In contrast, when justifying the exclusion of gay targets, participants were more likely to use conventional (God's law) reasoning or stereotypic assumptions about gay people (might hit on me, it's unnatural/disgusting).

The type of gender nonconformity further qualified differences in the use of justifications across sexual orientation. Table 2 highlights the hypothesized interaction. Participants used moral justifications less frequently (human equality), and conventional or stereotypic justifications more frequently (negates norms, God's Law, it's unnatural/disgusting), for straight targets whose appearance did not conform to expected gender norms compared to straight targets whose mannerism or choice of activity were nonconforming. When the appearance nonconforming target was gay, participants reported a higher use of the negation of norms. Participants also used more stereotypic justifications to justify the exclusion of activity nonconforming gay targets compared to mannerism nonconforming targets.

Female targets. The analysis revealed a main effect for justification for the female target scenarios $\left(F(10,5,590)=3.47, p<.001 \eta^{2}=.01\right)$. The main effect was qualified by a two-way interactions between justification and sexual orientation $\left(F(10,5,590)=2.50, p<.01 \eta^{2}=.004\right)$. The hypothesized three-way interaction between justification type, gender expression and sexual orientation was not significant.

Justifications for the exclusion of female targets differed based on the target's sexual orientation. Similar to male targets, participants tended to use more moral justifications for straight nonconforming targets, and more conventional or stereotypic justifications for lesbian nonconforming targets (see Table 1). 


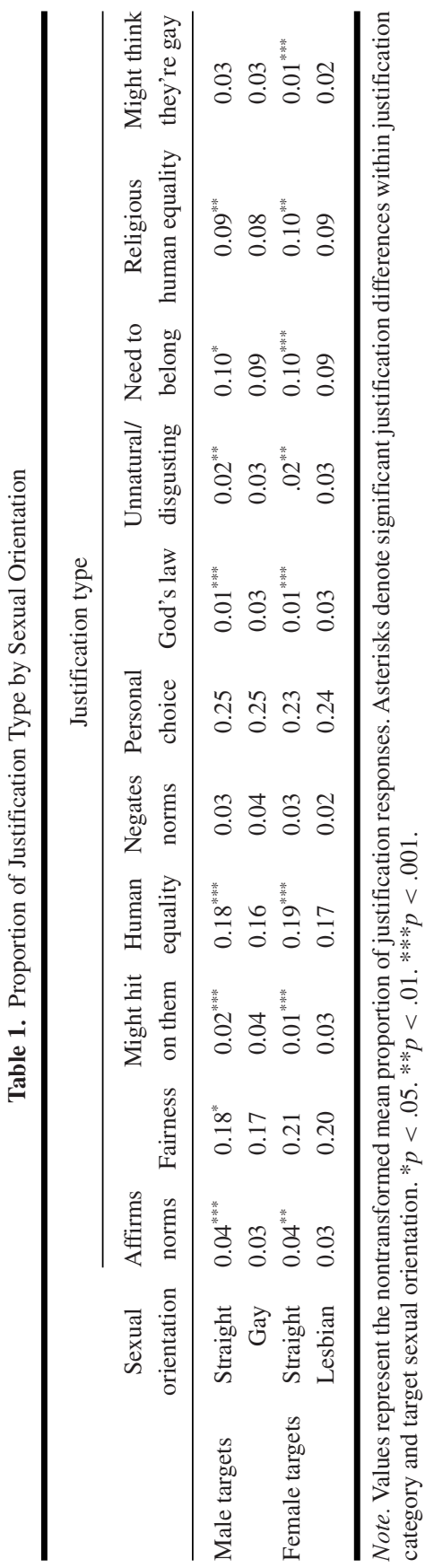




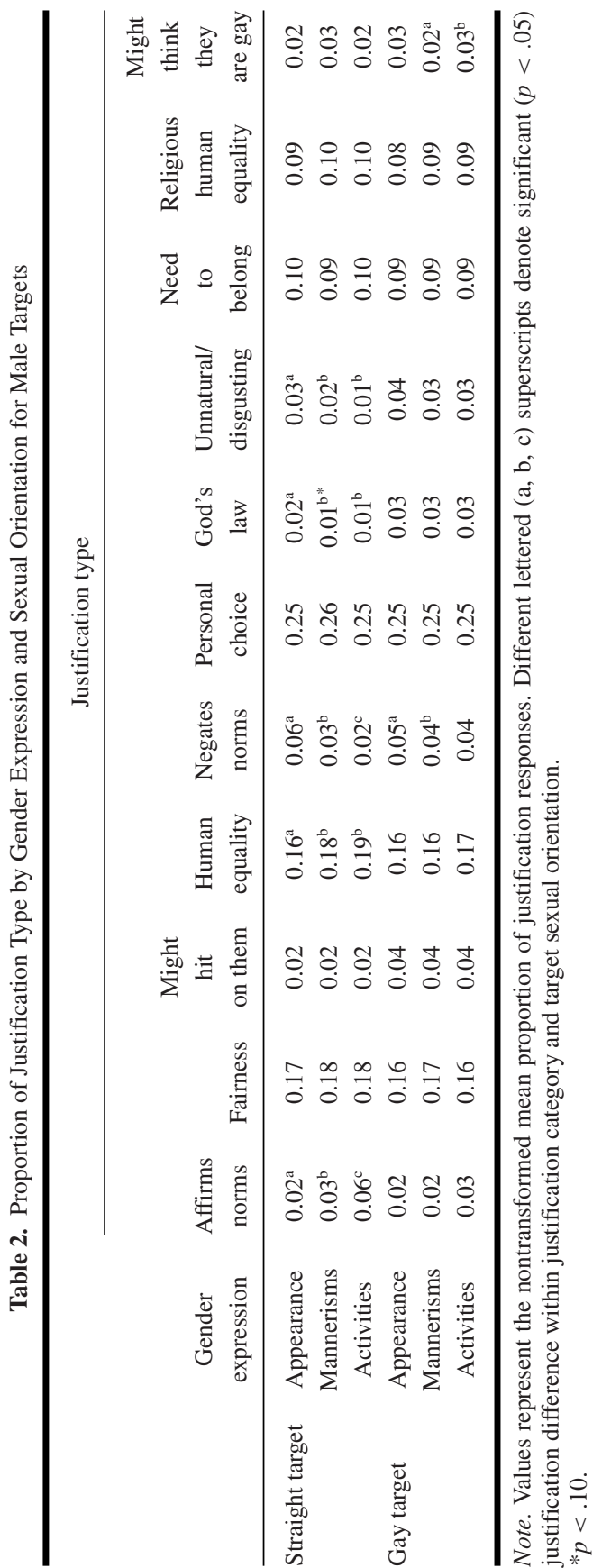




\section{Discussion}

The purpose of this study was to examine adolescents' attitudes about exclusion of gender nonconforming, heterosexual, gay or lesbian peers, as well as their reasoning behind their decisions. Earlier work has argued that children's and adolescents' reasoning about exclusion is multifaceted, domain specific and influenced by group identification (Rutland et al., 2010). Whereas exclusion based solely on race or gender, for example, is typically rejected on moral grounds (Killen \& Stangor, 2001), potential threats to group identity lead to more conventional rationalizations for exclusion (Rutland et al., 2010). Exclusion, then, serves as a regulatory mechanism within an intragroup context or a differentiation mechanism in an intergroup context. This study extends the social reasoning developmental perspective to instances of sexuality and gender expression-based exclusion and the role that conventional and moral reasoning play when evaluating exclusion of both gay and straight gender nonconforming peers.

Previous work on sexual orientation, gender nonconformity and peer victimization has argued that sexual orientation and gender nonconformity are independent pieces of information when making a decision about exclusion (Blashill \& Powlishta, 2009; Schope \& Eliason, 2004). Consistent with these findings, participants in our sample did generally report that it was more acceptable to exclude their gay or lesbian, as opposed to straight, peers. Our study expands on this previous research, however, by also providing evidence that gender nonconformity in appearance, especially for males, is a salient factor in adolescents' decisions about their peer interactions, regardless of sexual orientation. Certain types of gender nonconformity for males may be perceived as more deviant and more of a threat to the in-group, thus resulting in greater censure from peers, regardless of whether the individual is gay OR straight. Interestingly, this did not seem to be the case for girls who deviate from prescribed gender roles in any way.

At a time when both group conformity and physical appearance are especially salient (Carlson-Jones \& Crawford, 2006), appearance nonconformity in males was particularly susceptible to adolescents evaluating exclusion as OK. Straight male appearance nonconforming targets were not evaluated differently than gay appearance nonconforming targets suggesting that social norms regarding masculine appearance affect gay and straight males' peer interactions and relationships equally and is viewed by adolescents as the most deviant type of transgression of masculine gender norms. Deep-seeded gender socialization, which begins in childhood (Martin \& Ruble, 2002), may explain why exclusion of males who do not follow conventions for gendered appearance is evaluated as more legitimate, regardless of their sexuality. Maintaining the distinction between masculinity and femininity through exclusion may be a way to address threats to the in-group (i.e., "maleness") that transgressing masculine norms for appearance and dress may pose. In contrast, because females typically have relatively greater flexibility in 
gender role adherence (Schope \& Eliason, 2004), participants may have felt less of a need to regulate the actions of their female peers who transgress feminine gender norms.

Similar to previous research by Horn (2006a, 2007) and Poteat, Espelage, and Koenig (2009), this study provides additional evidence that adolescents use exclusion to regulate each other's personal expressions. More specifically, the type of reasoning adolescents used to justify their exclusion judgments varied based on the type of gender nonconformity the target expressed. When male targets were straight and appearance nonconforming, participants used conventional justifications more often for their judgments, whereas they used more moral reasoning for judgments regarding straight mannerism or activity nonconformers. This finding is interesting considering that, overall, participants were more likely to use appeals to conventions when considering why excluding a gay target (disregarding gender conformity) would be OK. When the appearance nonconforming target was gay, however, participants more frequently resorted to stereotypic justifications. This pattern of results may be linked to adolescents' stereotypes of gay men as more "naturally" feminine coupled with their underlying assumptions regarding the lack of normality of nonheterosexual forms of sexuality for males.

It is important to note that exclusion judgments across sexual orientation and gender nonconformity were below the neutral value, indicating that adolescents, overwhelmingly, believed that excluding a peer based on these attributes was wrong. Moreover, consistent with previous work on exclusion (Killen \& Rutland, 2011), respondents most often cited moral justifications for why exclusion was wrong. That said, differences in participant judgments and reasoning provide additional evidence that gay and lesbian adolescents face increased levels of social exclusion and prejudice because of their sexuality. In addition, the results extend previous research on exclusion and harassment related to sexual orientation by demonstrating that adolescents' judgments and reasoning about exclusion were also related to gender expression, particularly for males. Young men, and gay men in particular, appear to have even less flexibility in their gender expression lest they draw negative reprisal from their peers. In addition, straight males who violate norms regarding gender appearance faced prejudicial attitudes similar to their gay counterparts. Interventions focused on expanding adolescents' notions of what constitutes normative expressions of masculinity (and femininity) would benefit adolescents of all sexes and help to create a school environment that supports all individuals' identity expressions (see e.g., Pahlke, Bigler, \& Martin, 2014).

\section{Limitations and Future Directions}

Several design concerns potentially limit the extent to which our findings inform research on sexual orientation, gender conformity and exclusion. First, the absence of gender conforming conditions, which would serve as an 
important reference category, prohibits potentially interesting comparisons. Our results suggest certain types of nonconformity can lead to less tolerant judgments of peers than others; it is unclear, however, whether gay or lesbian gender conforming targets would be rated similarly based solely on their sexual orientation. It could be the case that gender conforming gay or lesbian targets are evaluated as more acceptable than certain (or all) nonconforming straight targets. Further, the nonconforming scenarios were not pretested to assess the degree to which participants evaluated the characters as nonconforming. Depending on the individual, the manipulation of appearance, mannerism or activity may have been viewed as normative. Previous work utilizing these scenarios, however, has noted differences in the extent to which adolescents view different characters as acceptable (Horn, 2003), supporting our view that adolescents would consider the characters as nonconforming.

Second, the use of a single item rating to measure participants' judgment of the scenarios may have masked more discriminating components of exclusion. For example, adolescents may consider exclusion of nonconfirming peers to be more appropriate in certain contexts compared to others (Horn, 2003; Killen \& Stangor, 2001). Further whereas our justification choices were informed by pilot studies and previous research, we did not include a self-report option for respondents. A more qualitative approach for collecting exclusion justifications may reveal multifaceted or complex reasoning around exclusion (e.g., reasoning that references multiple domains; is context and/or person specific; etc.). Future research could expand on the present findings by including design features that allow respondents to provide open-ended responses.

In addition, a particularly small number of participants identified as gay or lesbian and were thus excluded from the study because preliminary analyses suggest that they evaluated these issues differently than their peers who identified as heterosexual. Given that adolescence is a significant developmental period regarding sexuality, however, we recognize that a larger proportion of students may be exploring, questioning, or experimenting with nonheterosexual identities than identified as such on the survey, in part due to the stigma and sanction attached to these identities. Due to the nature of the method and the fact that we asked only one question about sexual identity (as opposed to additional questions about same-sex attractions or behaviors) our sample of "heterosexually identified" adolescents may have included students who were in the process of exploring same-sex sexuality or who identify as lesbian, gay, or bisexual but did not want to identify this way on a survey. In addition, because we did not ask individuals about their own gender identities or expressions, the sample may also have included young people who identify as transgender or are nonconforming in their own gender expression.

Though our results emphasize the interaction between sexual orientation and gender expression, it is likely that justification use is also influenced by participant age and gender. Researchers have noted age-related changes in 
adolescents' reasoning about issues of exclusion (Horn, 2003; Killen et al., 2002; Mulvey et al., 2014). Whereas Killen and colleagues have found an increase in the use of conventional and personal reasoning with age (up to 7th grade), in a study of 9th- and 11th-grade adolescents' reasoning regarding exclusion, Horn (2003) found a decrease in the use of conventional reasoning with age. This suggests that adherence to social norms in making decisions about peer interactions peaks in middle adolescence. Though further analysis of gender and age effects was beyond the scope of this article, future research should explore these relationships.

Finally, our research is cross-sectional, which limits the extent to which we can tie our current findings to individual development. Future research should consider repeated measurements of the same individuals as they mature from children to young adults. This type of research would allow us to better understand how developmental changes in social cognition interact with individuals' social judgments regarding their nonheterosexual and gender nonconforming peers during this dynamic period of development.

\section{Implications}

Within the United States (and globally), victimization of lesbian and gay young people at school is prevalent and has dire consequences for young peoples' overall health, development, academic engagement and achievement, and well-being (see Russell, Kosciw, Horn, \& Saewyc, 2010). The results of this study provide evidence, however, that this type of harassment does not affect only students who identify as lesbian or gay, but rather young people, particularly males, who fall outside of the prescribed expectations for "appropriate" masculine appearance, mannerisms, or identity expressions regardless of their sexual orientation.

These results have tremendous implications for advocacy work in schools related to creating safer environments for all young people regardless of sexual orientation or gender identity/expression in that they suggest that the entire school community, whether or not any students at the school are out as lesbian or gay, is affected by misogynistic and homophobic harassment. In fact, in his work on uncovering the correlates of the most deadly school shootings in the United States (e.g., Columbine), Michael Kimmel (2003) provides evidence that in almost every case he examined, the young men who perpetrated the shootings faced repeated and insidious gay bating and gay bashing at the hands of their peers, yet to date, none of the shooters in those cases identified as gay. Furthermore, in most of these cases the young men report that educators or their peers did little to stop this type of harassment or victimization from happening. The results of our study provide compelling evidence for advocates seeking to enact strategies and policies that reduce this type of harassment in schools. 
In addition, the results of this study provide further support that bullying and harassment are often based on bias and discrimination and that antibullying laws and policies should not only be enumerated (i.e., list protected identity categories covered by the legislation) but also that sexual orientation and gender identity and/or expression should be included within the list of protected categories. The results of our study suggest that young people use exclusion related to expectations regarding gendered appearance as a way to regulate intra- and intergroup interactions and are less likely to view this type of exclusion as unfair or hurtful. Including sexual orientation and gender identity/expression as protected categories within state level anti-bullying legislation and school-level policies sends a strong message to everyone within that state or school that these types of behaviors are wrong and that they are wrong because they are harmful to the educational and developmental well-being of individuals within those contexts. Our research provides evidence that including protections related to sexual orientation and/or gender identity/expression in schools will protect straight identified students who are victimized in these ways, and may also protect the entire school community by reducing the types of victimization that lead young people to engage in retaliatory violence against the community.

Schools should be places that young people experience as safe and supportive, but also in which young people can engage in finding solutions to contemporary and relevant problems, discuss complex and controversial issues, and interact and learn with others who are different from themselves. Because adolescents' social interactions with their peers, including social exclusion, require young people to coordinate knowledge from multiple domains of social reasoning, these types of conversations can serve to facilitate young peoples' navigation and constructed understandings of these issues ultimately helping them to understand how and when their interactions with each other may be hurtful and harmful to others.

\section{References}

Abrams, D., Rutland, A., \& Cameron, L. (2003). The development of subjective group dynamics: children's judgments of normative and deviant in-group and out-group individuals. Child Development, 74(6), 1840-1856.

Abrams, D., \& Rutland, A. (2008). The development of subjective group dynamics. In S. R. Levy, M. Killen (Eds.), Intergroup attitudes and relations in childhood through adulthood (pp. 47-65). New York, NY: Oxford University Press.

Alfieri, T., Ruble, D., \& Higgins, T. (1996). Gender stereotypes during adolescence: Developmental changes and the transition to junior high school. Developmental Psychology, 32, 11291137.

Baker, J., \& Fishbein, H. (1998). The development of prejudice towards gays and lesbians by adolescents. Journal of Homosexuality, 36, 89-100.

Blashill, A. J., \& Powlishta, K. K. (2009). The impact of sexual orientation and gender role on evaluations of men. Psychology of Men and Masculinity, 10, 160-173.

Carlson-Jones, D., \& Crawford, J. K. (2006). The peer appearance culture in adolescence: Gender and body mass variations. Journal of Youth and Adolescence, 35, 257-269. 
Carr, C. L. (1998). Tomboy resistance and conformity: Agency in social psychological gender theory. Gender \& Society, 12, 528-553.

Craig, W. M., Peplar, D., Connolly, J., \& Henderson, K. (2001). Developmental context of peer harassment in early adolescence: The role of puberty and the peer group. In J. Juvonen \& S. Graham (Eds.), Peer harassment in school: The plight of the vulnerable and victimized (pp. 242-262). New York: Guilford Press.

Fingerhut, A. W., \& Peplau, L. A. (2006). The impact of social roles on stereotypes of gay men. Sex Roles, 55(3-4), 273-278.

Heinze, J. E., \& Horn, S. S. (2009). Intergroup contact and beliefs about homosexuality in adolescence. Journal of Youth and Adolescence, 38, 937-951.

Herek, G. M. (1994). Assessing heterosexuals' attitudes toward lesbians and gay men: A review of empirical research with the ATLG scale. In B. Greene, G. M. Herek (Eds.), Lesbian and gay psychology: Theory, research, and clinical applications (pp. 206-228). Thousand Oaks, CA: Sage Publications, Inc.

Horn, S. S. (2003). Adolescents' reasoning about exclusion from social groups. Developmental Psychology, 39, 71-84.

Horn, S. S. (2006a). Heterosexual students' attitudes and beliefs about same-sex sexuality and the treatment of gay, lesbian, and gender non-conforming youth. Cognitive Development, 21, 420440.

Horn, S. S. (2006b). Group status, group bias, and adolescents' reasoning about the treatment of others in school contexts. International Journal of Behavioral Development, 30, 208-218.

Horn, S. S. (2007). Adolescents' acceptance of same-sex peers based on sexual orientation and gender expression. Journal of Youth and Adolescence, 36, 363-371.

Horn, S. S., \& Szalacha, L. A. (2009). School differences in heterosexual students' attitudes about homosexuality and prejudice based on sexual orientation. European Journal of Developmental Sciences, 3, 66-81.

Killen, M. (2007). Children's social and moral reasoning about exclusion. Current Directions In Psychological Science, 16, 32-36.

Killen, M., Lee-Kim, J., McGlothlin, H., \& Stangor, C. (2002). How children and adolescents evaluate gender and racial exclusion. Monograph of the Society for Research in Child Development, 67 (4, Serial No. 271).

Killen, M., \& Rutland, A. (2011). Children and exclusion: Morality, prejudice, and group identity. New York: Wiley/Blackwell Publishers.

Killen, M., Rutland, A., Abrams, D., Mulvey, K. L., \& Hitti, A. (2012). Development of intra- and intergroup judgments in the context of moral and social conventional norms. Child Development, 84, 1063-1080.

Killen, M., \& Stangor, C. (2001). Children's reasoning about inclusion and exclusion in gender and race peer group contexts. Child Development, 72, 174-186.

Kimmel, M. (2003). Adolescent masculinity, homophobia, and violence: Random school shootings, 1982-2001. American Behavioral Scientist, 46, 1439-1458.

Lehavot, K., \& Lambert, A. J. (2007). Toward a greater understanding of antigay prejudice: On the role of sexual orientation and gender role violation. Basic and Applied Social Psychology, 29, 279-292.

Mandel, L., \& Shakeshaft, C. (2000). Heterosexism in middle schools. In N. Lesko (Ed.), Masculinities at school. Thousand Oaks, CA: Sage.

Martin, C. L., \& Ruble, D. (2002). Cognitive theories of early gender development. Psychological Bulletin, 128, 903-933.

Mulvey, K. L., Hitti, A., Rutland, A., Abrams, D., \& Killen, M. (2014). When do children dislike ingroup members? Resource allocation from individual and group perspectives. Journal of Social Issues, 70(1), 29-46.

Nucci, L. (1996). Morality and the personal sphere of actions. In E. Reed, E. Turiel, \& T. Brown (Eds.), Values and knowledge (pp. 41-60). Hillsdale, NJ: Lawrence Erlbaum

Pahlke, E., Bigler, R. S., \& Martin, C. L. (2014). Can fostering children's ability to challenge sexism improve critical analysis, internalization, and enactment of inclusive, egalitarian peer relationships? Journal of Social Issues, 70(1), 115-133. 
Pascoe, C. J. (2011). Dude, you're a fag: Masculinity and sexuality orientation in high school. Los Angeles, CA: University of California Press.

Poteat, V. P., Espelage, D. L., \& Koenig, B. W. (2009). Willingness to remain friends and attend school with lesbian and gay peers: Relational expressions of prejudice among heterosexual youth. Journal of Youth and Adolescence, 38, 952-962.

Poteat, V. P., Kimmel, M. S., \& Wilchins, R. (2011). The moderating effects of support for violence beliefs on masculine norms, aggression, and homophobic behavior during adolescence. Journal of Research on Adolescence, 21(2), 434-447.

Russell, S. R., Kosciw, J. G., Horn, S. S., \& Saewyc, E. (2010). Safe schools policy for LGBT students. Society for Research in Child Development Social Policy Report, 24, 1-25.

Rutland, A., Killen, M., \& Abrams, D. (2010). A new social-cognitive developmental perspective on prejudice: The interplay between morality and group identity. Perspectives on Psychological Science, 5, 280-291.

Schope, R. D., \& Eliason, M. J. (2004). Sissies and tomboys: Gender role behaviors and homophobia. Journal of Gay \& Lesbian Social Services: Issues in Practice, Policy \& Research, 16, 73-97.

Thorne, B. (1993). Gender play: Girls and boys in school. New Brunswick, NJ: Rutgers University Press.

Turiel, E. (1983). The development of social knowledge: Morality and convention. Cambridge, England: Cambridge University Press.

Winer, B. J., Brown, D. R., \& Michels, K. M. (1991). Statistical principles in experimental design. New York: McGraw-Hill.

JUSTIN HEINZE, is a Research Investigator in the Department of Health Behavior and Health Education at the University of Michigan. He earned his $\mathrm{PhD}$ in educational psychology from the University of Illinois at Chicago in 2011 and a BA and MA from the University of Michigan. His primary research interests include belonging motivation and developmental transitions in adolescence and emerging adulthood. He is also interested in the formation of social judgments that lead to social exclusion/ostracism or prejudicial behavior, and how valence in social climate affects individuals' mental and physical health.

STACEY S. HORN, is a Professor of Educational Psychology in the Department of Educational Psychology. She received her PhD from the University of Maryland in Human Development. Dr. Horn is interested in peer groups and intergroup relations; stereotypes, prejudice, and discrimination related to sexual orientation and gender identity, as well as the relationships among institutional structures and adolescents' social and moral reasoning. Stacey is on the editorial boards for the Journal of Youth and Adolescence, International Journal of Behavioral Development, and the Journal of Gay and Lesbian Youth. Her research has been published in journals such as Developmental Psychology, the International Journal of Behavior and Development, Cognitive Development, and the Journal of Youth and Adolescence. 